\title{
The WISCONSIN GARDEN BOOK
}

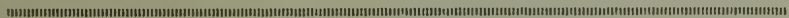

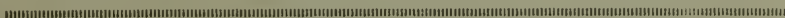

Published by

The Wisconsin State Horticultural Society

Madison

1922 



\section{THE WISCONSIN GARDEN BOOK}

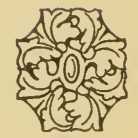

Published by

The Wisconsin State Horticultural Society

Madison

1922 


\section{SB321 . W72}

\section{FOREWORD}

While the lessons in this garden booklet were prepared for the guidance of beginners in gardening the experienced gardener may, perchance, profit by reading them.

Nothing contained herein is new; the subject matter has been published again and again as supplements to Wisconsin HoRTICUlture and the practices described are as old as the art of gardening. The only merit claimed is brevity. No unnecessary words have been used and it is believed few of importance have been omitted.

Many writers, all practical gardeners, have contributed to these pages, so many that it is unfair to name one without naming all. We will call it then, A Wisconsin Garden Book, for Wisconsin Gardeners, by Wisconsin Gardeners.

Frederic Cranefield,

Secretary State Horticultural Society.

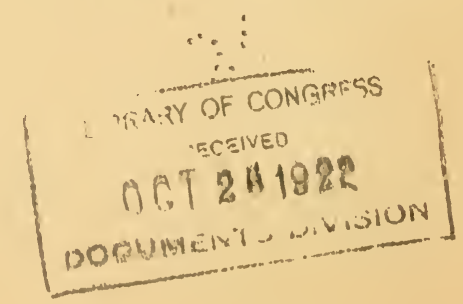




\section{GETTING READY FOR THE GARDEN}

Don't waste your effort next summer in gardening in competition with trees and shade. It can't be done successfully. Hoeing, watering and fertilizing cannot make up for lack of sunlight. Many gardeners try to make this substitution and fail. Good garden tracts may be spoiled by worthless, often self-planted, trees or shrubs. Cut them out so your vegetables will not have to compete with them for sunlight, food, and water. You will probably find, also, that your back yard looks better without them.

It is well to remember that although trees on the north side of the garden do not shade it yet their roots often extend far into the plot and take food and moisture from the soil, making it unprofitable to plant fruits and vegetables near the base of the trees.

If it is impractical to remove the offending plants, or if buildings shade your garden for the greater part of the day begin at once to make arrangements for a suitable garden tract. Ask the aid of the local organization which is helping to get gardeners and the garden tracts together.

\section{The Garden Plan}

What kind of a house would a carpenter build without a plan? How would a garden which was planned, row by row, while the planting was being done compare with one carefully planned in advance of planting? The professional gardener finds a plan necessary for best results. A definite plan is of even more importance for the small garden if the best results are to be secured. Haphazard, hit-or-miss garden planting usually results in poor use of the soil and lessened production. A good plan saves much valuable time at planting because the gardener doesn't have to stand around and figure out where things are to go.

As soon as you know where your garden is to be, measure your tract and then plan your garden on paper. A good working plan should show: 
1. Location of the different crops.

2. Distances between rows.

3. If more than one crop is to occupy the same area during the season.

4. Approximate dates for making different plantings of lettuce, peas, radishes or other vegetables of which more than one planting is made.

Use heavy paper and ink so that your plan will stand a season's use in the garden.

It is well to use a definite and fairly large scale in showing distance between rows. For a small garden one-fourth or one-half inch on the plan to every foot in the garden is a convenient scale. The more carefully your plan is made the greater will be the returns from your garden.

In making a garden there are certain things to remember.

1. Make every foot of land work all the time. As soon as one crop is harvested another shou'd take its place if there is room for its proper growth. Practically all of the garden should grow two crops and part of it ought to produce three. Warm season crops such as beans and tomatoes, and late seeded crops like turnips may follow early cool season crops such as lettuce, spinach, radishes and onion sets.

2. Vegetables which can be stored for winter use should be considered first. The vegetables will be more appreciated when the supply is low and the price is high.

3. First plan for the long season crops-the short selason crops will take care of themselves. Grow short season crops (lettuce, radishes, spinach) between the rows of long season crops. Globe radishes may be grown in the rows of carrots, parsnips and beets. Small, early-maturing vegetables can be grown between the young plants of cabbage, tomatoes, or corn in hills.

4. If your garden is small you cannot afford to grow crops requiring lots of space. Potatoes, corn, and vine crops should usually be left out of the small garden. If these are grown the smaller, quick-growing crops should occupy the space until it is needed by the permanent crop.

5. Foliage crops (lettuce, spinach) are likely to do better in partial shade than the fruit crops (tomatoes, beans).

6. Do not plant high-growing plants (corn, tomatoes to be staked) where they will shade sun-loving plants. The diffi- 
culties arising from shading can be greatly lessened by having the rows run north and south.

7. Unless you have had previous experience do not waste much time on cauliflower, peppers, egg plant or other crops that are hard to grow or of doubtful value. These crops so often fall due to weather conditions or slight errors in culture that it is usually advisable to give their space to more certain crops.

8. Remember that in a small garden there is plenty of space "up and down" but it is limited sidewise. Tomatoes should be trained to trellises or stakes. Tall growing peas trellised and planted between rows of smaller vegetables require no more space than dwarf varieties and usually produce larger crops. If you think you must grow cucumbers try the trellis method.

9. Leave sufficient space between the rows to provide for good tillage. It is better to have slightly too much than too little space. The beginner will need a wider space between the rows than the experienced gardener. Be on the safe side.

\section{Space Needed for Various Vegetables}

The distance between the rows will vary with the method of cultivation, the size of the variety, and the fertility of the soil. The distances given below are for hand or wheel-hoe cultivation and average fertile soil.

8- 9 inches-Peas when planted in double rows.

9-12 inches-Radish.

12 inches-Cress.

12-15 inches-Beets, carrots, lettuce, onion, spinach.

15-18 inchẹs-Bush beans, endive, parsley, rutabaga, salsify, turnip.

18-20 inches-Parsnips, pepper.

18-24 inches-Cabbage (early), chard, kohlrabi.

24-30 inches-Cabbage (late), peas, tomatoes (staked).

30-36 inches-Egg-plant, potatoes, sweet corn.

30-48 inches-Celery (depends largely on method of blanching).

42-48 inches-Squash (bush), tomatoes (unstaked).

4- 6 feet-Cucumber.

5. 6 feet-Muskmelon.

7- 9 feet-Squash (running).

8-10 feet-Pumpkin. 
When vegetables of different kinds are planted in adjoining rows the distance between the rows should be approximately one-half of the total distance allowed for the crops. For example, if celery, for which is allowed 4 feet between rows, and cabbage, for which a distance of 2 feet is allowed, occupy adjoining rows the distance between the rows should be about 3 feet.

\section{Time Crops Occupy Land}

The length of time between starting the crop in the garden and that at which it is ready to use and the time it will occupy the land are important factors in garden planning. Seasonal conditions and the variety will greatly modify the time required for vegetables to be ready for use.

The following list shows the average time needed to grow the different vegetables. In planning for crops to follow early vegetables or which will occupy the space used by an early crop, add to the time given in the table below the probable length of time required to use the early crop or the length of time required for it to become unfit for use.

The dates given are the approximate dates of planting at Madison. For the central part of the state the dates would be from 10 to 12 days later, and for upper Wisconsin 18 to 20 days later.

In the table which follows, * placed before the name of a crop indicates that other plantings may be made; ** indicates that the crop occupies the land until the end of the season. In case of $* * *$ other plantings may be made as the crop is used, but the winter crop occupies the land until the end of the season. Early cabbage will occupy the land until August 15 or later. 


\begin{tabular}{|c|c|c|}
\hline Crop & $\begin{array}{l}\text { Approximate date of } \\
\text { planting at Madison }\end{array}$ & $\begin{array}{l}\text { Ready } \\
\text { for uso } \\
\text { (weeks) }\end{array}$ \\
\hline 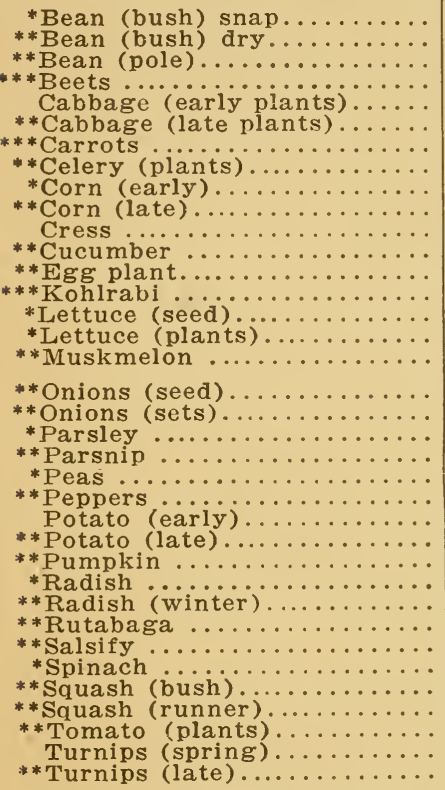 & 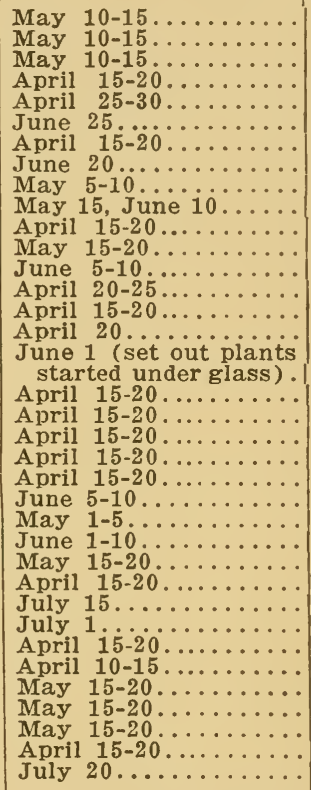 & 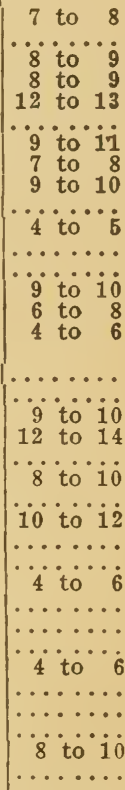 \\
\hline
\end{tabular}





\section{HINTS FOR THE HOME GARDENER}

The beginner in gardening is apt to attempt too much. A small garden well tilled is better than a larger one neglected.

Amateur or home gardens may be divided into two classes: the small back lot gardens ranging in size from $6 \times 10$ feet to those of as many yards, and the gardens of the more ambitious amateurs occupying an entire lot or even more.

\section{To Plant or Not to Plant}

In the small garden confine the list to kinds requiring but little room such as:

Bean, beet, cabbage, carrot, lettuce, onion, parsnip, pea, radish, spinach and tomato. Not much more should be attempted except that late turnips or rutabagas may be grown as succession crops.

These Demand Much Elbow Room-Sweet corn, cucumber, squash and pumpkin require much room and with potatoes should be attempted only where plenty of land is available.

These Are Too Fancy-Brussels sprouts, cauliflower, endive, egg plant, peppers and lima beans are kinds that require rather more skill to grow than the average amateur is apt to possess and should not be included in the beginners' list.

Soil conditions and the taste of the gardener are factors that should be considered.

The beginner is usually very ambitious and is apt to try everything named in the catalog. The old-timer confines his efforts to a few kinds, the ones most in demand in the kitchen.

\section{The "Best" Varieties}

Ask each of a dozen expert gardeners to make a list of "best" varieties and the result will be a dozen different lists, for each has his favorites, but on discussion it will usually be found that their distinctions are too slight to be considered seriously. All the important garden vegetables are 
classified by the expert as to types, such as the round radishes and the long radishes, round beets and flat beets, etc. Each seedsman has varieties which he exploits as the "best" of these types.

The following lists may not include the best kinds in the opinion of many expert gardeners but all are standard, reliable and thoroughly tested and at least plenty good enough for anybody:

Bean, Dwarf: Refuge wax; Refugee 1000 to 1 (green pod). Pole or climbing: Cranberry or Horticultural; Kentucky Wonder. The last two varieties are climbing or pole beans and are recommended where space is very limited. The Cranberry, a climbing or pole variety, is very prolific and partly matured beans shelled are as good as Lima Beans.

Beet: Detroit dark red or Crosby's Egyptian. The first named is round, the second, flat or turnip shaped.

Cabbage: For early cabbage Charleston Wakefield, for late Danish ball head and Copenhagen market.

Carrot: Chantenay: This is a half-long carrot and better adapted to home gardens either for summer use or cellar storage than the Oxheart or other large types.

Kohl Rabi: White Vienna.

Lettuce: For early "leaf" lettuce either Curled Simpson or Grand Rapids. The Grand Rapids is rather better in quality than the Simpson, but does not grow as rapidly nor stand as much hardship. The Grand Rapids is ideal for hotbed culture.

For first crop head lettuce plant only May King; for late season California Cream Butter.

Onion: Yellow Globe Danvers or Southport Red Globe.

Parsnip: Hollow Crown.

Pea: Laxtonian: This is one of the best of the large podded, early dwarf peas and may be sown in succession. Little Marvel is a good early. For a late maturing variety plant Champion of England, Telephone or Stratagem. The latter are tall growing kinds and require support.

Radish: Early scarlet globe or any early round or turnip shaped variety sown in succession. For a later variety Crimson Giant; does not get "pithy" in hot weather.

Rutabaga: American Purple Top.

Spinach: Bloomsdale Savoy. 
Tomato: Chalk's Early Jewel; Bonnie Best; Late Stone.

Turnip: Purple Top White Globe; the Yellow Globe is a large late maturing yellow flesh variety, closely resembling rutabaga and of better quality.

\section{Plants or Sets}

For early onions plant onion sets. For early cabbage and tomato buy plants; plants for late cabbage may be easily grown in the garden; plant a packet of seed at the time of sowing early vegetables.

For the Gardener Who Has Plenty of Room and Time

Cauliflower: Early Snow Ball.

Celery: White Plume.

Cucumber: Improved Long Green.

Sweet Corn: Golden Bantam.

Egg Plant: Black Beauty.

Lima Beans: Burpee's Bush Lima, or Henderson's Bush Lima.

Muskmelon: Milwaukee Market.

Parsley: Champion Moss Curled; (Six plants enough).

Peppers: Crimson Giant (sweet).

\section{How to Buy}

Buy seeds only from reliable seedsmen. They advertise in reliable papers. Avoid "bargains" in seeds, the best is the cheapest. The cost of seed is not a big item considering the returns. Penny packets and department store bargains are to be avoided.

\section{Quantity of Seed Required}

The problem of how much seed to buy is one beset with many difficulties and not easily solved.

If we were certain that every seed we buy would germinate and produce a vigorous plant under the adverse conditions of soil and climate commonly encountered, we would need to buy but very little seed.

Carrots, for instance, should be spaced at least two inches apart in the row for best results. A package of carrot seeds contains about 5000 seeds which spaced at two inches would be enough to plant over 800 feet of row. In practice an average packet is enough to plant a little less than 40 feet 
of row. Why use so much seed? Firstly, because not all seeds will germinate and as all the poor seeds may fall in one place we must allow enough to insure a good stand.

Secondly: Conditions in the garden are never perfect for germination and growth and many of the plants perish before reaching daylight.

Thirdly: Seeds must be covered with earth, which is a dead weight that must be lifted by the plantlets. We must, therefore, plant seeds enough to afford lifting power to break the surface crust.

Fewer seeds are required when sowing later in the season than for earlier sowings, as the ground is then more mellow and seeds come up easier.

As amateur gardeners are interested only in small areas, ounces and quarts may be left out of consideration and attention directed mainly to packets of seed. In order to learn something of the actual size or contents of "packets" offered by reliable seedsmen, 31 packets of seed were purchased from four seed firms and the seeds in each counted. The results follow:

\begin{tabular}{|c|c|c|c|c|c|c|c|c|}
\hline Seedsman & : & 苋 & $\begin{array}{l}\ddot{\Delta} \\
\stackrel{\Delta}{0} \\
\oplus\end{array}$ & $\begin{array}{l}\text { శ్ } \\
\text { Фొ } \\
\oplus\end{array}$ & $\begin{array}{l}\stackrel{\Im}{0} \\
\stackrel{0}{0}\end{array}$ & 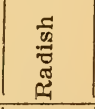 & 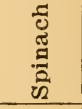 & 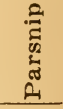 \\
\hline $\begin{array}{l}\mathrm{A} \\
\mathrm{B} \\
\mathrm{C} \\
\mathrm{D}\end{array}$ & $\begin{array}{r}1210 \\
1016 \\
910 \\
1690\end{array}$ & $\mid \begin{array}{l}5427 \\
3 \dot{7} \dot{2} \dot{0} \\
\ldots \ldots\end{array}$ & $\begin{array}{l}335 \\
500 \\
356 \\
585\end{array}$ & $\begin{array}{r}156 \\
265 \\
258 \\
94\end{array}$ & $\begin{array}{l}257 \\
394 \\
340 \\
169\end{array}$ & $\begin{array}{r}1032 \\
1408 \\
1108 \\
790\end{array}$ & $\begin{array}{l}777 \\
990 \\
440 \\
782\end{array}$ & $\begin{array}{r}1126 \\
850 \\
700 \\
1892\end{array}$ \\
\hline Average..... & $1206+$ & $4573+$ & 444 & $193+$ & 290 & $1084+$ & $747+$ & 1142 \\
\hline
\end{tabular}

Combining these figures with the experience of skilled gardeners as to the proper number of seeds to plant per inch or foot, one packet of onion seed will plant 10 feet of row, carrot 40 feet, beet 29 feet, bean 20 feet, pea 25 feet, radish 10 feet.

Summing up it may be said that for the average family garden one packet of seed is enough of any of the kinds named except possibly peas and beans. By careful sowing one packet of most of the vegetables named is more than enough for the first planting and some may be saved for later planting. 


\section{EARLY PLANTS}

It is possible to have a garden without starting part of it indoors, but it is usually more expensive or less satisfactory.

Of course if you are abso.utely sure you are going to be able to buy good plants of the kinds you want, when you want them, then it may be best to let someone else grow them. But be very sure you won't be disappointed. Although it takes some work and space to grow good plants for setting out for early vegetables, the difficulties of growing them are often greatly magnified.

Lettuce, chard, cabbage, and kohlrabi can be easily matured if seed is planted in the garden after conditions have become favorable for their growth, but they may be had much earlier if started indoors or under glass. It is almost essential to start tomatoes, peppers, egg plant, and celery in this way if their production is to be such as to make it worth while to bother with them.

\section{Methods of Growing Early Vegetables}

Three methods are commonly used in producing plants for setting in the garden: Hotbeds, cold-frames and window boxes. The difficulty of securing the proper material for heating the hotbed, and the attention necessary to operate it successfully, make it of questionable value to the man with a small garden or to the beginner.

Many city lot gardeners find the cold-frame more satisfactory. While plants cannot be secured quite so early as with the hotbed the cold-frame requires less attention and there is less danger of injury to the plants because of changing temperatures. It can be constructed without much expense by using storm sash. In addition to the plants for setting out, such crops as lettuce and radishes may be grown in it.

The backyard gardener will usually find that starting the plants indoors is the plan best adapted to his conditions. Comparatively little space will be required to start enough plants for the first crop of lettuce, early cabbage and tomatoes. 
Provide Good Soil. Where no provision was made last fall the question of the soil will be the most troublesome. You may be able to secure it from a greenhouse. If not resort to your own garden. Get the snow off a small area so as to encourage thawing. Some warm day in early March get your soil. If it is still frozen get it anyway, and let it thaw out indoors. If possible, secure a little sand to mix with it and to serve as a top layer in the seed box. Before attempting to start your seed box let the soil warm up and dry until it does not pack in a hard lump when squeezed in the hand.

Shallow Seed Box. A shallow box is most satisfactory for starting the plants. Suitable ones can usually be secured at a grocery store. Cigar boxes $2 \frac{1 / 4}{4}$ or $2 \frac{1}{2}$ inches deep are convenient, but somewhat deeper boxes are more desirable. Three or four will be sufficient to provide all the lettuce, cabbage and tomatoes used in the average garden. If the box has a tight bottom make a few small holes in this to provide drainage.

Filling the Seed Box. Slightly more than enough soil to fill the box should be put in loosely and the surplus scraped off with a stick. This will leave the top smooth and level. Press the soil down, preferably using a small piece of board, being careful to leave the surface level. After it is pressed down, the top of the soil should be from one-fourth to onehalf inch below the top of the box. If sand is to be had a better stand of plants will usually be secured if the last onehalf inch of soil put into the box is sand. In this layer the seed may be sown.

Sowing the Seeds. With the finger or a dull pointed stick make a shallow trench about one-fourth of an inch deep, preferably crosswise of the box. Using the packet or thumb and forefinger, scatter the seed in the trench. The thickness of sowing the seed depends largely on its germination capacity. Do not sow too thickly as there is then more danger of the young plants rotting off. On the other hand, seeding should be thick enough to give a good stand. If the plants are too thick they should be thinned soon after they come above the surface. Press the seeds gently into the soil and cover them with a thin layer of soil. The distance between the rows depends somewhat on how long the plants are to be left before transplanting. Distances from $1 \frac{1 / 4}{4}$ to 2 inches are usual and convenient. 
Watering the Seeds. After sowing, water the seed box well, being careful not to wash the seed, particularly if different varieties are to be grown in the same box. Enough water should be put on to moisten the whole body of soil in the box but not enough to cause it to become muddy.

One of the objections often raised to growing early plants indoors is the damage resulting to furniture and rugs from watering. This can be overcome by setting the seed boxes in the sink or some other receptacle until all excess water has drained off. Then if the boxes are set on oil-cloth or heavy paper no damage should occur.

Now cover the seed box with a pane of glass or other cover, which will prevent the loss of moisture and set the box in a warm place. As soon as the young plants break the soil, remove the cover. If it is left on, the plants have a tendency to become spindly or "leggy," and are likely to rot off.

Care of Young Plants. The young plants will need careful attention as regards proper light, heat and water. Keep the seed box where it will get abundant light. Insufficient light results in spindly plants. It is better to have the temperature a little low than too high. High temperatures mean soft, spongy plants which are less likely to give good results when set out.

How to Water Plants. More people fail in watering than in any other way. Some choke the plants, others drown them. Choking usually comes from applying small amounts at rather frequent intervals. Not enough water is applied to moisten the bottom soil, and the top is kept too wet, which encourages disease.

Drowning is less frequent, especially if the seed box is provided with drainage openings. Water applied frequently in large amounts excludes air from the soil and the plants smother.

Proper watering consists in putting on enough water to moisten all the soil in the box and then waiting until the surface of the soil begins to appear lighter in color before making another application.

Damping off. Young plants that seem to be in good condition sometimes begin to die in spots. The disease usually causing this condition is called "damping off" and unless it is checked all the plants may be killed. 
This disease is usually present in soil used in seed boxes unless it has been sterilized. It becomes active when the temperature is high and there is a large amount of moisture in the air around the plants or on the surface of the soil of the seed box. Proper watering, of course, will reduce the danger from "damping off."

The disease should be checked as soon as it appears. Affected plants that have fallen over should be removed but care must be taken not to spread the disease. The next thing is to get rid of the excess moisture by setting the plants in the sunlight and allowing the soil to become quite dry. One of the chief reasons for using sand in the top layer of the seed box is that it dries off readily so that there is less danger from "damping off." Another way to dry the surface is to sprinkle dry sand over it. Plants should be thinned out if they are so thick that there is little circulation of air between them. Another method of control is to spray the plants with potassium sulfide solution-1 to 2 ounces of sulfide to one gallon of water-but this is usually not necessary if other methods of control are promptly used.

Giving the Seedlings Room. The young plants will soon begin to crowd each other and unless given more room will become long-stemmed or "leggy." To make good plants for setting out they must be either thinned or transp'anted. The latter is the more common method. A box 12 inches square will hold 36 plants set 2 by 2 inches, or 64 when planted $1 \frac{1}{2}$ by $1 \frac{1}{2}$ inches. Four boxes of this size, one for tomatoes, peppers and egg plants (if either of the latter are grown), one for lettuce, one for cabbage and cauliflower, and one for celery would meet the demands of the average gardener. The celery may be planted 1 by 1 inch, lettuce, cabbage and cauliflower $1 \frac{1}{2}$ by $1 \frac{1}{2}$ inch, and tomatoes, egg plants and peppers 2 by 2 inches. The same general care should be given the plants after transplanting as when they were in the seed box. For two or three days after transplanting it is well not to give so high a temperature nor so full light as before transplanting.

Hardening Off. Many have success in growing plants indoors but lose a large portion of them in setting into the garden. Anyone of a number of things may be responsible for such losses. One of the common ones is subjecting the plant 
to too sudden and great a change. A plant requires some time to adjust itself to new conditions. Because of this it shou:d be accustomed to the conditions of the garden gradually. This process is known as "hardening off." Ten days to two weeks or more before time for setting the plants in the garden begin to get them ready for the change. Begin by setting the box out in the sun at noon for a few minutes. Repeat from day to day when favorable until the plant can be left out continuously. Transplanting will then result in much less loss than if a sudden change is made.

Where plants which transplant with difficulty, such as cucumbers and melons, are started indoors, or when it is desired to have the plants unusually large before setting out, flower-pots are frequently used. Unless the gardener has a hotbed or cold-frame or the number of plants desired is small, this method is not practical because of the space required.

Instead of setting the plant from the seed box into a larger box it is put in a small flower-pot. It may remain in the pot until set in the field, or it may be moved to a larger pot. Various devices are used as substitutes for pots. Two of the more common are the bottomless strawberry box and a tin can with the bottom removed and the side split, so that it may be readily removed from around the plant. The strawberry box is better than the can for this purpose. 



\section{GARDEN SOILS AND GARDEN MAKING}

The soils expert groups soils, with fine distinctions, into many classes. The farmer and the gardener call them "light" or "heavy," "rich" or "poor," "warm" or "cold" soils.

In the language of the farmer a light soil is one containing more sand than clay. It is easily worked either in spring or summer, and is also a warm soil for it absorbs heat more readily than a clay soil. But as a rule, sandy soils are lower in plant food elements than are the heavier soils.

The heavy soil is one having more clay than sand and in proportion as the clay predominates it is heavy and cold but it usually contains abundant plant food.

It is plain, then, that an ideal garden soil is one that is neither very light nor very heavy. It does not follow, however, that we should fail to have a garden even if the ideal soil is not available. Some very excellent gardens have been made on very unpromising sites. It's largely a matter of hard work.

\section{Don't Disturb Much Subsoil}

Below the 4 to 8 inches of mellow, usualiy black, surface soil of tilled land lies a different kind of soil called the subsoil. It is not mellow because it has probably not been stirred for at least ten thousand years. It is usually red clay. Sometimes it is blue clay. Whatever its color gardeners should leave it undisturbed and not turn much of it up on the surface of the garden by too deep spading. An inch or two won't do any harm. It contains plant food but usually in a form that is not available until sunshine, rain and wind have acted on it for a few years. You can't afford to wait so leave the subsoil where it is; it will hold water for your plants next summer.

\section{Make Haste Slowly}

No matter what kind of soil you have in your garden it must not be worked when it is wet. If it is it will be hard, lumpy and wholly intractable all season. You will lose and not gain by working soil before it is fit to work. 
When is it fit? There is no hard and fast rule but here is a simple test that will answer all practical purposes.

Turn up a spadeful of soil, grab a handful and squeeze it. If it retains the shape of your hand and the finger marks, and is smooth and pasty-like to the touch, it is not fit. If you cannot squeeze the mass lightly without breaking it, if it crumbles in your hand, go ahead, there is no time to lose. Such a rough and ready, off-hand solution of so difficult a problem as this requires the application of common sense along with it but the writer feels perfectiy safe in leaving it in just this way.

\section{First Aids to the Gardener}

(1) If your garden is anywhere but on a side hill you can probably advance by several days the t:me when it will be fit to work by a little digging and ditching so as to carry off the surface water. This should be done as soon as the frost is out of the ground.

(2) Instead of spading or plowing the entire garden before it is fit, it is usually possible to find an odd corner somewhere on the premises, even if only $2 \times 4$ feet, that is higher and drier than the garden. Maybe it is the flower bed in the front yard or a border alongside the house. Dig and rake this and plant a little lettuce seed and a little radish seed, or mix them, and a few onion sets. This emergency garden will serve as a curb on your very natural impatience, give some early vegetables and will not interfere in the least with flower gardening later in the season.

(3) Or, cover a space in the back yard, $4 \times 6$ feet, with coal ashes a foot deep and on top of this 2 to 4 inches of soil. This quantity of dry soil can usually be found somewhere nearby, even if borrowed from a high spot in a neighboring lot or field. Build around this garden a rough frame of boards, sow seeds, and cover frame nights and on coid or rainy days with two storm windows or, lacking these, with cheese cloth. Whatever else you do keep out of the garden until the soil is fit to work.

\section{Manures}

The soil of almost any garden is capable of producing satisfactory crops without manure of any kind if properly pre- 
pared in the spring and poperly cultivated during the growing season.

The right kind of manure properly applied will certainly give increased yields but the wrong kind may be worse than none at all. The right kind is well-rotted stable manure; it is fine in texture and mixes readily with the soil. Also it is "pre-digested"; the plant food contained in it has been made ready, by the process of decay, for use by the plants.

The wrong kind is fresh stable manure containing much straw or litter. This must all be turned under so deeply that the plant roots do not get to it until midsummer or it interferes with cultivation. Being coarse it serves to "dry out" the soil by interfering with the movements of soil water. Better use none at all.

\section{Commercial Fertilizers}

Of the mineral fertilizers, sodium nitrate and potash are best. The various stock-yards products including pulverized sheep manure, are quick acting fertilizers that may either be mixed with the soil when spading or plowing or used later as a top dressing.

Mineral fertilizers must be applied with great caution to growing plants, as in slight excess they may kill the plants outright. $\left(3 / 4\right.$ to $1 \frac{1 / 2}{\mathrm{lbs}}$. of nitrate of soda per square rod is enough. Of acid phosphate 2 to $2 \frac{1}{2} \mathrm{lbs}$. per square rod should be sufficient.)

These are all very expensive and seldom give adequate returns to the amateur for the money invested in them.

None of these statements should be construed as an argument against the use of fertilizers. The market gardener knows that he can make money by using extraordinary quantities of fertilizers; in fact he is not apt to make much money unless he does use a liberal amount. Your case is different; you are not so much concerned about making a profit on your land and time as in growing a respectable crop of vegetables. You can do it without any fertilizer if you handle your soil right.

\section{Coal Ashes}

Heavy soils may be much improved by a liberal use of coal ashes. Unless much wood has been burned in the fur- 
nace in addition to the coal there is no danger in using too much. It is better to sift the ashes to remove clinkers which prove a source of annoyance when hoeing. Coal ashes contain little or no fertility.

\section{Plowing}

Small plots, say 20 by 50 feet or even larger, may be spaded, but when the plot exceeds one-tenth of an acre and is so situated that a team can be used it will pay to have it plowed if it can be properly done.

A farmer knows how to plow, but the average city man who happens to own a plow, doesn't. He thinks he does, but he doesn't. If possible, get a farmer, or an ex-farmer to plow; you won't need to tell him how to do it; he knows more about it than you do. If you are so unfortunate as to get a city farmer to plow suggest to him that all of the soil ought to be turned over; that a plow that is made to cut only 10 or 12 inches cannot by any possibility turn 16 or 18 inches, the rest will merely be covered by the soil really plowed. This is the "cut and cover" trick, a money maker for the man who is plowing by the job but poor business for the gardener. Further suggest to him that it is a saving of horse flesh to plow only 4 to 6 inches deep rather than to root around in the clay subsoil and turn it on top. This will please him and help you.

\section{The Harrow}

If the garden-to-be is sod, plowing is not enough. The time and strength required to work down tough, sod-plowed land with handtools is really more than the crops that can be grown on it will be worth. A disk harrow will thoroughly pulverize and level the ground after plowing and is the best tool to use. In lieu of this a heavy spike-tooth harrow may be used but once is not enough. Five or six times will be much better.

\section{Spading}

There is a knack of spading that can be acquired only by practice. It is quite as easy to cut and cover as in plowing. The spading fork with four flat tines is better than a spade 
for digging; it is lighter, penetrates hard soil easier than a spade and is easier to keep clean and bright. A gardener who has had long experience in spading describes the process as follows:

"Strong shoes with good solid soles should be worn when spading or the feet will become sore."

"Start at one corner of the garden with the back toward the ground to be spaded. Shove the spade well into the ground using the ball of the foot to push the spade in. In solld ground, especially in starting, several shoves may be necessary to send the spade well in. Lift out the spadeful of soil and throw it from you across the hole, turning it over as it is thrown out. If lumpy, as it is apt to be, hit it with the back of the spade. Move sideways the width of the spade and repeat the operation until the other side of the garden is reached. Then step back and work over to the starting side again, but throwing the dirt this time forward into the ditch made the first time across. Take as large a spadeful as may be sliced off quickly and easily."

\section{Raking}

If spading is a knack, raking a freshly dug garden is a fine art. By a proper use of the rake lumps are broken and the surface leveled. Of this the expert quoted above says:

"Level the ground and make the soil fine with a hand rake. The use of a rake offers opportunity to develop considerable skill in moving dirt quickly from high spots and filling in low places in the operation of raking.

"If the garden is small and maximum results from the space are desired, further working of the soil will pay. If the soil is of a heavy clayey nature and the spading and raking fail to break up the lumps we usually 'tramp' the ground to further break the lumps. That is, we step back and forth over the garden with footsteps close together so as to pack the soil and crush lumps. A roller would do the work more quickly and easily. It is then raked over again, and, if necessary, we spade and rake it a second time.

"Even in the gardens that have been plowed with a horse it will often pay to spade up corners not well plowed or that have been heavily packed where the horses have turned. 
"All of the garden will not be planted immediately following the first working of the soil and if the surface is packed with beating rains it must be worked over again before planting.

"It is very important that the soil be in the best possible condition before seeds and plants are put in.

"No amount of after cultivation will make up for careless work in the first preparation of the garden."

This cannot be emphasized too much, especially in the case of the smaller seeds. The infant of the plant world is not unlike the infant of the animal world; it must be afforded the best possible opportunity for development. 


\section{SOWING THE SEED}

\section{Part I. The Art of Seed Sowing}

Seed sowing usually proves a stumbling block to the beginner in gardening. He gets along very nicely after the plants are up but his trouble lies in getting them started.

There are apt to be many vacant rows in the beginner's garden, while he waits impatiently for the plants to appear and blames the seedsiman for selling poor seeds. In most cases the seed is all right; the trouble lies with the planter. More failures result from improper planting than from poor seeds.

\section{Making a Seed Bed}

For the best results the soil must be mellow, moist, and free from lumps. If the surface has dried since plowing or spading and is lumpy it will pay to turn over two or three inches of the surface soil with a spading fork so as to have a moist and mellow bed for the seeds. Then rake and rake again until the surface soil, for a depth of at least two inches, is fine and mellow. In this connection let us quote from Circular No. 4.

"It is very important that the soil be in the best possible condition before seeds and plants are put in." No amount of after cultivation will make up for careless work in the first preparation of the garden.

\section{Have Straight Rows}

Rows should be straight, not alone for the sake of appearance but for convenience in cuitivating. In small gardens the garden line is most practical. Hemp rope of clothesline size is excellent. Use strong stakes that can be driven with the back of the spade. With the line drawn taut make a furrow, deep or shallow according to size of seeds, using a pointed stick or end of hoe handle. 


\section{Dropping the Seed}

To sow seeds by hand evenly is an art that can be acquired only by considerable experience. If, in the beginning, the seeds are poured from the paper packet into a cup, both temper and seeds may be conserved. The cup is not apt to blow away and spill the seeds.

Grasp a pinch of seeds between the thumb and forefinger and scatter with a rolling motion. That's about all that can be set down in print about it; the rest must be learned from experience. The expert will space seeds by this method as evenly as a seed drill and without apparent effort.

The amount of seed to sow has been discussed. No hard and fast rule can be given. Better use too much seed than too little.

Cover the seeds with the back of the rake, pushing lumps aside when possible so as to cover only with fine soil. Now press the soil firmly over the seeds either by stepping lightly along the row, one foot only, or patting firmly with the back of the hoe. This is held the most important step in seed sowing. After firming the soil rake lightly to form a mulch.

\section{Marking the Rows}

Set pegs or stakes at both ends of rows as soon as seeds are covered. In this way the space between the rows may be hoed or raked to keep down weeds before the plants appear. The best time to kill weeds is just before they appear and a light hoeing or raking within a week after seed sowing may save much backache later.

For information that will serve as a guide for operations another season the variety and the date of planting should be written heavily in pencil on the head stake of each row.

These directions and cautions as to careful preparation of soil have particular reference to small seeds like lettuce, radish, turnip, and onion, as these need a fine seed bed. Larger seeds such as beet and spinach will come through very well if the soil is not quite so fine, but they will appreciate the better treatment.

In making furrows for peas, beans and corn use a corner of the hoe. Practice counts here also. 
"Seeds should not be planted deeper than is necessary to insure the proper degree of moisture."-Goff. If we keep in mind that the reason we cover seeds with soil is to insure the moisture essential for germination it helps us greatly in determining the proper depth for planting.

The depth of planting may be regulated largely by the size of the seed. Large seeds may be planted deeper than small ones. (One important exception to be noted later.)

No definite rule can be given. Any table giving in inches or fractions of an inch the depths at which seeds should be planted is misleading, for much depends on the texture and tillage of the soil; the amount of moisture it contains, the date of planting and other variable factors. One rule, subject to many exceptions, is to cover seeds three to five times their diameter (thickness).

Small seeds like carrots, lettuce, radish, cabbage and turnip, ought to be covered with one-fourth to one-third inch of soil. If the soil is very light (sandy) they ought to be planted a little deeper to insure moisture sufficient for germination. Beet, spinach and parsnip may be covered deeper, one-half inch if the soil is not too heavy. Peas and corn should be covered with about two inches of soil, beans not over one inch. Beans lift the seed above ground and if planted too deep will break their necks in the effort to get through. For this reason something is to be gained by planting in hills; that is, four to six seeds in a place, these a foot apart. If planted singly, space $1 \frac{1 / 2}{2}$ to 2 inches apart. Do not plant peas in "hills" but singly, about an inch apart.

\section{Odds and Ends}

A "hill" in garden language does not mean an elevation but refers to a number of seeds planted in a group rather than singly in a row.

Cucumbers, melons, squash, and so forth, are commonly planted in hills by the market gardener for convenience in cultivation. There is no good reason for doing it in the small garden. Plant the seeds flatwise 1 to 2 inches apart, the plants to be thinned later, and cover one-half inch deep. 
Seeds planted in midsummer for succession crops, should be covered somewhat deeper than when planted in the spring, in order to insure needed moisture. The soil will be more mellow and warmer than in the spring-both factors favoring germination.

Peas as well as corn and others of the "grass" family will push through greater depths of soil than beans and others that project the seed or seed leaves above the ground.

Germination (sprouting) of seeds may be hastened by soaking in water 24 to 36 hours before planting. Soaked seeds should not be allowed to become dry before planting.

The potato is not a seed and scarcely anything here written applies to it. Cut the potatoes into pieces, each having one or more "eyes" or buds, and plant the pieces singly 10 to 12 inches apart in furrows 4 to 6 inches deep.

\section{Part II}

\section{Reasons for Some of the Operations Described in Part I}

Every seed contains an embryo plant. In order to germinate (sprout) and produce a living plant three things are essential-moisture, warmth and air (oxygen). If any one of these is lacking, seeds will fail to germinate. If any one of these essentials is not present in sufficient amount, germination will be tardy. It is very important that seeds should germinate promptly or else decay will result.

Seeds absorb water promptly when placed in contact with it. In the soil the promptness and rapidity with which seeds absorb moisture will depend upon the points of contact. If the soil is not pressed closely about the seed but few points are in contact with it and a long time will be required for it to germinate. Therefore, we tramp the soil over the seed with the foot or hoe. By this means we also increase the capability or water pulling power of the soil, for moisture passes readily through soil particles which are in close contact and less readily when the soil is loose.

The proper degree of warmth is essential. This varies with the species but the variation is not wide.

Seeds of the common garden vegetables will germinate readily at a temperature of 50 to 55 degrees. Lettuce and radish will germinate at a lower temperature, 45 to 50 de- 
grees. Peas will germinate at 32 to 40 degrees. Cucumber and squash seed require 60 degrees.

These figures are close to the minimum or lowest temperature. The most favorable temperatures are 5 to 10 degrees higher in all cases. It is useless, therefore, to plant seeds in soil that is too cold.

Water drives air out of the soil. Working wet soil "puddles" it, shutting out air. Seeds will not germinate in soil that is too wet and will germinate very slowly in puddled soil. 



\section{INSURE YOUR HARVEST}

The gardener's faith may be shown by the manner in which he tilis his garden. The summer months are the critical ones in the garden. Though the gardener may feel less inclined to hoe and rake than he did earlier in the season, the plants demand even closer attention if the table is to be supplied during the summer and the cellar is to hold an abundant supply of vegetables next winter.

The gardener's motto at this time should be "Catch moisture; hold moisture." The demand for moisture as the plants grow and the warmer weather comes on constantly increases, moisture is needed for plant growth, and unless there is an abundant supply, growth ceases and the parts used for food fail to develop or are of such a nature as to be undesirable. Moisture, then, becomes the chief concern of the gardener at this time. Tillage is the chief means the average gardener has of insuring this essential of successful gardening.

But the demand for moisture is not the only one made by the plant at this time. An abundance of available plant food is necessary for good yields. The manure or commercial fertilizer which is applied in preparing the soil will be of no use to the plant unless it becomes changed in the soil. Tillage not only aids in this change but it also helps make the food material, originally held in the soil particles, suitable for use by the plant.

The old saying "Tillage is esentially manure" and "The best garden fertilizer is the hoe" indicate the value of tillage in giving the plant an abundant supply of available food.

Weeds cause many a garden convert to backslide. In the conflict with weeds tillage is of prime importance. Proper tillage makes weeds an unimportant factor in gardening. Under some conditions it may not do so the first season, but unless quack grass or some weed of similar character is the offender, the conflict is a comparatively easy one.

The importance of tiliage makes the summer months the "Three T" period of gardening - the thorough, timely, tillage period.

\section{[31 ]}


Conserving soil moisture, making plant food available, and keeping out weeds are the objects of tillage. Thorough tillage is that tillage which produces conditions best fitted to accomplish these results. The ideal way to accomplish them is to keep a shallow layer of soil, as nearly dustlike as practical, over the entire surface of the soil at all times. The method of securing this ideal matters little so long as the purpose is accomplished.

The first essential of success is proper preparation tillage early in the season. This should have been such as to create a large moisture-holding reservoir and to put the soil in a fine, fairly loose condition. If this was done, the following program is well adapted to maintain the desired mulch.

1. Till the area to be planted immediately preceding sowing or planting. This gives a good seed bed and removes the necessity of disturbing the seeds after planting.

2. Till the area between the rows immediately after planting. The object is to loosen the soil compacted by tramping during the planting operations.

3. Till the entire garden at least once a week if soil conditions permit. When vegetables planted close together cover the entire area between the rows tillage of these rows may cease.

4. Till after each shower of sufficient extent to pack the surface soil.

This tillage should be shallow. Deep tillage wou.d destroy many roots and possibly do more harm than good.

Remember the object to be attained is a shallow layer of soil as nearly dustlike as practical over the entire surface.

\section{Timely Tillage}

"Don't put off till tomorrow what should be done today" pays big dividends if put into practice in gardening. "A stitch in time saves nine" when garden conditions are most favorable for tillage.

Aim to destroy weeds just as they appear above the surface. It will save hard work in getting rid of them later.

The soil mulch destroyed by a rain is restored much more easily by tillage before the surface becomes baked. A few 
hours' delay at this time means more work and usually less satisfactory results than if the work had been done on time.

Tillage may be untimely by working a soil which is too wet. Heavy loam or clay soils worked when too moist, cement or puddle and then bake. Their tilth is destroyed, and it becomes difficult or impossible to re-establish a good soil mulch. "Make haste slowly" on heavy soils after a rain. Timely tillage on such soils means not tilling too soon, as well as not delaying too long, after a rain.

If in doubt, take a handful of soil and squeeze it firmly. Tillage is safe if the soil falls apart or crumbles easily when the hand is opened. If the particles adhere tenaciously let it dry more before tilling.

\section{Tillage Tools}

The best tillage tools are the ones you can use most effectively in establishing and maintaining the soil mulch. Gardeners have their likes and dislikes regarding tools. What suits one does not suit another, but in any case the list does not need to be extensive.

The spading fork is better than the ordinary spade for use in preparing the soil and will often be found useful even on gardens that are plowed. The hoe and rake are the chief tillage implements in the average small garden. If they are of the proper kind and properly used no others are necessary. The Norcross type of cultivator saves much time and does efficient work if properly used, and there is less danger of doing poor work with it than with the hoe.

More than half the garden hoeing is less than half done. This is because most inexperienced and many experienced gardeners do not know how to use the hoe as a tillage implement. The aim in hoeing should be to leave the entire surface fine, loose and level; hoeing properly done stirs all the soil possible. Many gardeners fall short of this by pulling a quantity of soil on top of a nundisturbed area. This leaves the surface in small hills and hollows. Then the hills are raked into the hollows and only about half the area is covered with an effective soil mulch. Operate the hoe not only so as to stir all the soil but also to leave it level and fine. In most hoeing the soil is moved too far.

Many a gardener becomes so intent in hoeing that he overlooks the purpose of the hoeing. It does little good to estab- 
lish a soil mulch and to destroy it immediately by tramping the loosened soil. Aim to have as few footprints visible after the hoeing is finished as practical. With this purpose in mind you will quickly devise ways of reducing the tramping without loss of time or efficiency in tillage.

The small hoe and narrow rake are preferable to the larger sizes. They are easier to operate, can be used closer to the pants, and, if the soil is compact, better work can be done with less expenditure of energy. A three-cornered hoe with the handle attached at one corner (an onion hoe with a long handle) serves as both hoe and weeder, and does as good or better work with greater ease than the hoe with a large blade or the hand weeder.

The garden rake, is essentially a "preparation tillage" tool but can be substituted for the hoe when the rows are far enough apart to permit of its use. Used with a slight chopping motion it saves time in establishing a soil mulch. The straight rake with straight teeth is preferred.

The time saver in maintenance tillage is the Norcross type of hand cultivator. It is built on the plan of the wheel hoe or horse cultivator but is operated by hand with a motion similar to that used by most people in hoeing.

Resolve to make your garden investment pay maximum dividends by thorough, timely tillage. 


\section{PROTECT YOUR GARDEN}

If it is worth while to plant a garden, it is worth while to protect it. Insects cause heavy losses to garden crops where no effort is made to control them, while a few simple measures applied at the right time will usually entirely prevent such losses.

One of the first things to do in the spring is to get the garden and fence corners free from weeds. At all times of the season gather up and destroy all old vines, stalks and refuse as soon as the crops are harvested. Refuse and weeds furnish food for insects and shelter them for the winter if left in the garden.

Do not let insects get a start. After they once become numerous on the plants it does not take long for them to do a large amount of injury, especially on young plants. Every insect that you let live through the spring season will produce many more later.

Where insects are few in number and are easily seen, they may be controlled by hand picking and destroying. But in most cases it is much more practical to spray the piants.

Liquid sprays may be applied with a small hand sprayer which can be bought at a small cost. Dust sprays may be dusted through a cloth sack, or perforated tin can or by means of a dust gun.

\section{Use Poisons on These}

Poison sprays, poison mashes, or contact sprays may be used to eradicate certain garden pests. Here are some of the most common insects, together with the poisons to use on each of them.

Chewing Insects. Insects that eat the leaves and tender parts of the plants may be controlled by spraying the plants with lead arsenate at the rate of 1 ounce ( 15 level teaspoons) to each gallon of water. When applied to plants with smooth foliage, such as cabbage, it is necessary to add an inch cube of common laundry soap to every gallon of spray to make it 
spread and stick better. Instead of using it as a spray, lead arsenate may be dusted on the plants early in the morning while they are still wet with dew. When used in this way it may be diluted with 3 to 5 times its weight of air-slaked lime or fine dust. Lead arsenate is preferable to Paris green because it remains on the foliage longer, is not so likely to burn the leaves, and is cheaper.

Cutworms cut off young plants near the surface of the soil and eat the foliage of older plants, feeding at night and hiding on the ground during the day. A small number of plants may be protected by cutting the tops and bottoms out of tin cans and placing them over the plants, pushing them well into the soil. Keeping down weeds and thorough cultivating of the soil is also of value. Larger areas may be protected by applying poison bran mash to the soil in the late afternoon or early evening. Either broadcast the material or place in little heaps near the bases of the plants. Care should be taken to keep poultry and livestock away from it.

To make up the poison bran mash mix 2 ounces Paris green or white arsenic or 4 ounces of arsenate of lead with 3 pounds of bran. Add 2 ounces of cheap syrup or molasses, $1 / 2$ orange or lemon finely ground and a small quantity of water. Then mix all together, adding enough water to make a crumbly mash. One half teaspoon lemon extract may be used instead of fruit.

Grasshoppers may be controlled by poison bran mash made up as for cutworms. Tomatoes or melons may be substituted for oranges or lemons. The mash should be applied in the early morning so that it will not dry out before the insects feed on it. If the grasshoppers keep coming in from neighboring grass fields, scatter the mash along the edge of the garden toward the field and renew from time to time.

Plant lice are small, soft-bodied insects which may be found massed together on the under sides of leaves and on tender shoots. They injure the plants by sucking the juices and for this reason cannot be controlled with arsenate of lear. They may be controlled by applying some contact spray, such as strong soap (preferably fish oil soap) at the rate of one-half pound to 4 gallons of water; or 40 per cent nicotine sulfate (Black Leaf 40 ), 1 teaspoon to 1 gallon of water with the addition of an inch cube of soap. The spray must actually cover 
the insects and should be forced well into curled leaves. If all are not killed by the first application, the spray should be repeated.

\section{Kill These Directly}

Some common garden insects cannot be reached or controlled by sprays, and must be removed by gathering the insects and destroying them, or by destroying their eggs.

Squash bugs cannot readily be controlled by means of sprays. They will collect under pieces of board or burlap and may be gathered and destroyed early in the morning. The reddish brown eggs are laid in clusters on the under sides of the leaves and may be gathered and destroyed.

\section{BE CAREFUL OF POISONS}

Lead arsenate, white arsenic, and Paris green, recommended in this circular, are deadly poisons, and care should be taken to keep them away from children and domestic animals. Bean plants should not be sprayed after the pods have formed, nor tomatoes after the fruit is nearly full grown. There is no danger of poisoning to the consumer from eating sprayed cabbage because the cabbage head grows from the inside and the outer leaves are removed before cooking. The outer leaves, however, may have enough poison on them to kill domestic animals.

\section{Repellants Keep These Out}

Many insects which cannot easily be poisoned or killed direct:y may be kept out of the garden to a greater or less extent by the use of repellants-which keep the insects away, even though they do not kill them.

Root Maggots. The cabbage maggot may be controlled on cabbage and cauliflower plants by placing tarred felt discs about the stems of the plant at the surface of the soil, just as they are being set out. After the maggots have begun to work on the roots there is no practical remedy. 
For maggots attacking onions, radish and turnips no satisfactory remedy has as yet been found. Infested plants should be puiled up and destroyed. Small beds of these may be grown under cheesecloth screens.

Tarnished Plant bugs, dull grayish to brownish pests about $1 / 4$ inch long, fly readily when disturbed and cannot be controlled with sprays. They may be driven from the garden by dusting the rows with wood ashes, working from one side to the other.

Flea Beetles. These little black jumping beetles are quite often serious on potatoes, tomatoes, cabbages, beans, and similar plants. Arsenate of lead seems to have little effect on them, but they can be kept away from the plants with Bordeaux mixture. This is made up as follows: 4 ounces bluestone, 4 ounces quicklime, 12 quarts water. Disoslve the bluestone in a wooden or earthenware vessel, using hot water, then add water to make 6 quarts. Slake the lime by adding water a little at a time. When slaked make up to 6 quarts. Pour the two solutions together through a strainer whie stirring. The spray is then ready to apply. Both the upper and lower leaf surfaces should be covered. A combination of Bordeaux mixture and poison may be used.

Cucumber Beetles. These yellow and black striped or spotted beetles are also not easily affected by poison, but their food plants, such as cucumber, squash, and melons, can be made unattractive to them by dusting with a mixture of powdered lime and tobacco dust. Mix 1 pound of tobacco dust in 2 pounds of well-pulverized lime and dust the mixture onto the plants using a gunny sack or a tin can with small holes in the bottom. A small number of plants may be protected by placing cages over them. These cages may be made by cutting barrel hoops in two, nailing the halves together at right angles to each other, and covering with cheese cloth. Planting a large number of seeds per hill will help to get a better stand. 


\title{
STRAWBERRIES AND RASPBERRIES FOR HOME AND MARKET
}

\author{
Raspberry Culture
}

Two kinds (species) of raspberries are commonly cultivated for home use and for market, the red and the black-the latter known as blackcaps or simply "caps."

These kinds, aside from their color, differ in the manner in which they are propagated.

Red raspberries are propagated by "suckers" which grow from the roots of the parent plant. In the black-caps plants grow from the tops of the branches when these are covered with soil or are held in place by a lump of earth or other means.

Soils: Raspberries thrive best on deep, well drained soil, clay loam with clay subsoil or on gravely clay loam; in other words, well drained "cool" soils. Don't plant raspberries on thin, gravelly, or light sandy soil and expect to raise profitable crops.

For paying crops apply plenty of stable manure.

\section{Red Raspberries}

The culture of the red raspberry is influenced at every step by its habit of producing suckers or shoots from the roots. The first year of its growth a number of suckers will develop from the parent plant but not more than needed. The following year, however, and each succeeding year, innumerable suckers will spring up, not only close to the plants but between them and in fact wherever the roots extend. It is plain that this surplus growth of plants must be restricted or the field will soon become merely a brush patch, yielding little or no fruit.

\section{Hills vs. Matted Row}

Two methods of culture are in common use by growers, the hill and the matted row. Good paying crops may be grown by either method. 
In the case of the hill system the plants are set 2 to $21 / 2$ feet apart and the rows 6 feet apart. After the first season the suckers are confined to hills, 8 to 10 shoots or "canes" allowed to grow and all others removed.

In the matted row the plants are set 12 inches apart in the row and the suckers allowed to form a matted row 12 to 15 inches wide and the canes 6 to 8 inches apart. The matted row usually yields more fruit than the hill system.

\section{Setting the Plants}

One method of planting is to plow shallow furrows for the rows, after the field has been plowed and harrowed, then set the plants the required distance and cover the roots, using a hoe or spade and tramping firmly about the roots. If the ground is mellow three to four inches of soil over the roots is enough and not too much.

If a large field is to be planted and a number of planters work systematically no doubt the furrow method will save time but the average planter will set by hand, using a spade.

Cut back the tops at planting time, leaving only short stubs. Where available a plant-setting machine commonly used for setting tobacco and cabbage plants, can be used successfully if a special, larger and deeper cutting hoe is used.

As the season advances a number of shoots or suckers will appear. These develop into plants which may produce a little fruit the following year.

\section{Pinching}

Some growers advise pinching the growing shoots the first season when about eighteen inches in height to encourage branching, but this is not an important matter. Something may be gained by pinching but certainly no harm will result if it is not done. Cutting back the matured canes the following spring is a matter of the highest importance as will be shown later.

\section{Cultivation and Intercropping}

The ground should be kept clean and mellow all the season by frequent cultivation and hoeing. Vegetables may be grown between the rows the first season but don't plant strawberries 
between raspberry rows, as the strawberry plants will interfere with cultivation or mulching of the raspberries the following season when it is most needed. Number of plants required: Three thousand six hundred and thirty plants are required for an acre when planted 2 by 6 feet.

\section{Black Caps}

Black caps require rather more room than the reds. The reds are upright growers while the blacks are more spreading in habit. Three feet is close enough in the row and strong growing varieties ought to have even more room. The rows may be 7 feet apart. An acre planted 3 by 6 feet requires 2,420 plants.

In contrast to this, one successful grower plants black-caps eighteen inches apart in the rows and renews the plantation at the end of three years, taking only one full crop.

\section{Planting}

The "tip" plant of the black raspberry as received from the nursery is a flattened, compact bunch of fine roots with a single stem arising from the center. Around this stem are numerous buds that develop into other stems or "canes." If this bud cluster is covered too deep with heavy soil the buds will not push through. We are therefore confronted with the problem of covering the roots deep enough so they will not dry out and shallow enough to avoid smothering the buds. It can be done and the least difficulty will be experienced in soil that has been well prepared before planting.

Cultivation the first season is much the same as for the reds except that the black caps do not form suckers from the roots. The only canes or stems that grow will be from the bud cluster mentioned above. Usually there are not too many of these the first year, five or six, and are all retained.

As in the case of reds there is no objection to growing an annual crop between the rows the first season. Two rows of beans, one row of potatoes or other root crops, may be grown between each two rows of raspberries without serious detriment to the berry plant.

No fruit will be borne the year the plants are set out, either on reds or blacks but every effort should be made to secure a 
strong, healthy growth of plants. Deep, rich soil and thorough cultivation will produce such plants. But little fruit will be borne the year following planting, the second growth year, but thorough cultivation must not be neglected for starved plants will never bear profitable crops. The second year after planting, third growth year, one-haif a normal or full crop may be expected and a full crop the next succeeding years.

A raspberry plantation should yield profitable crops for four to six years. Many plantations are fruited for a longer period, eight to ten years or even longer, but in the opinion of many successful growers, the expense of cultivation in these older fields, the difficulty of securing a vigorous growth and the accumulation of insect and disease pests render it unprofitable to fruit raspberries longer than five or six years.

\section{Trellis}

It has been the universal practice in the past to build a trellis or support for raspberry plants, both red and black, but this is now rarely done. Growers have now learned that properly pruned plants require no trellis or other support. This subject of pruning will be discussed later but mention is made of it here as a matter of encouragement to beginners.

Varieties: As in the case of other fruits, opinions of growers differ widely when it comes to selecting varieties. The following kinds are popular with Wisconsin growers:

Red-Marlboro, King, Cuthbert, in the order named.

Black-Plum Farmer, Cumberland, Gregg, as named.

\section{Other Kinds}

Purple Raspberries-The Columbian, Shaffers Colossal and perhaps other varieties, strong growing kinds sometimes producing canes twelve to fifteen feet in height and an inch or more in diameter, bearing purplish fruit, are hybrids produced by crossing the red and the black raspberry.

The purple or purple-cane raspberries are better adapted to the home garden than to growing for market. They are not more productive than the red or the black, the rank growth interferes' with proper cultivation and involves greater expense in picking. Also the very unattractive color of the fruit lessens its market value. 
Everbearing Raspberries-The so-called everbearing raspberries are to be classified with the everbearing strawberries, interesting and attractive to the amateur, but of little value to the commercial grower. The Saint Regis is the best known of the everbearing type.

\section{After the First Year}

The suggestions so far given include only planting and care the first season.

Reds: During the first season the reds should make a growth of 18 inches to 2 feet. The following spring these young canes shouid be topped or cut back to a uniform height of about 18 inches. In the spring of the next and following years the canes should grow to a height of three to five feet and these should be cut back, in the spring, to a height of thirty inches. Weak and diseased canes should be removed.

Pruning improves the quality of the fruit. If all the buds are left more fruit will set than the plant can properly mature. If the plants are not pruned the fruit will be borne so high as to suffer from wind and will also increase the difficulty of picking it. It is also probable that the quantity of the fruit is increased by pruning.

As stated above the number of canes retained for fruiting should not be more than eight to ten if in hills or closer than six to eight inches if in a matted row and the row twelve to fifteen inches wide. This caution to cut out surplus plants of the red raspberry confining the growth for fruitage to a comparatively few canes and these severely cut back every spring cannot be too often repeated.

Black Caps: The black caps at the end of the first season should have two to five stout canes to each hill, more or less branched, two to three feet in height. After the first year the canes may attain a height of five feet, much branched and curving to the ground. These stems or canes should be pruned as in the case of the reds. The cutting shouid consist in shortening the branches which spring from the main stems one-half or more, or if not branched in cutting the canes back to a height of twenty-four to thirty inches.

Cultivation: Cultivation for the second and succeeding seasons should be the same as for the first season, clean, thorough 
cultivation to keep the soil stirred and to keep down weeds and grass.

Mulching: If stable manure or other coarse material is available in sufficient quantity it will pay'to apply it heavily around the plants every year. This mulch will serve to keep down weeds, conserve moisture and add fertility.

\section{Caution}

The raising of raspberries for market in Wisconsin at the present time promises to be a profitable business and it is very unlikely that it will be overdone in the near future. At the present time the acreage has so far decreased as to be almost negligible."

While the policy of the Horticultural Society at the present time is to encourage the planting of berries, both to benefit growers and in order that there may be a plentiful supply of this delicious fruit, those who intend to plant are invited to carefully consider the following points:

Only those who have a natural aptitude for this kind of work or in lieu of this recognize the fact that gardening and fruit growing require vastly more work per acre and closer attention to details than farm crops and firmly determine on close application to these details, should engage in it. Given this aptitude or its equivalent in determination to succeed there are other essentials: suitable soil, proximity to market and available pickers.

The question of market should be considered relatively. If the ultimate market is one hundred miles distant and the berry field one-half mile from a shipping point it may be a nearer market than one requiring a haul of ten miles to a point where the berries go on sale.

Fifteen to twenty good pickers will be required for each acre of red raspberries in full bearing and it is a matter of first importance that these be available every day during the fruit picking season.

Now if these requirements seem formidable none are incapchle of accomplishment. 


\section{Strawberry Culture}

The purpose of this article is to help the beginner; it is not designed as a treatise on strawberry growing and no attempt will be made to distinguish between growing for home use and for market as the methods are the same in both cases.

Soils: Any soil that will produce a good crop of corn will produce a good crop of strawberries. Strawberries are grown for market in Wisconsin on light sandy, gravely loam, black prairie and light clay soils and successfully in all cases. The physical properties of the soil are of less importance than drainage and fertility.

Site: Level ground is best for strawberries or any other fruit crop. A few days in earliness may be gained by planting on a south slope or ripening may be retarded somewhat if the plantation is on a north slope but the difference is so slight that it rarely offsets the added expense and inconvenience of cultivation on sloping ground and the necessity of planting so as to avoid erosion. The mid-season varieties are the most profitable ones for Wisconsin growers.

The so-called early varieties are shy bearers and as a rule lack vigor. These värieties may yield a few early berries but rapidly fall off and cannot be depended on for the main crop.

Preparation of Soils: Don't plant strawberries on sod land, that is, land on which grass was grown for two or more seasons, as such soils are quite sure to be infested with the white grub which will feed on the roots of the strawberry plants.

Land intended for strawberries should be plowed in the fall and only lightly disked or harrowed in the spring just before planting, as newly set strawberry plants do not start well in soil that is very loose and mellow.

The choicest selection for a strawberry field is land that was heavily manured the previous season and planted to corn, potatoes or other cultivated crop and fall plowed. Under these conditions the manure is thoroughly incorporated into the soil and weeds are subdued to a large extent.

Manure: Strawberries require a soil rich in plant food in order to produce paying crops. It will be a waste of time to plant for market on thin, worn out soils without first manuring. If stable manure can be had apply ten to twenty-five loads per acre. 
It should not be inferred from this that all land must be heavily fertilized with stable manure before planting as an average farm or garden land that has been fairly treated as to fertilizers in former years will produce a good crop of plants the first year, if thoroughly cultivated.

Plants and Planting: Runner plants of the preceding year's growth are the only ones that should be used. Plants that have once borne fruit are not suitable, scarcely worth planting. Nurserymen furnish only runner plants. If plants are received from the nursery packed tightly in bundles, open the bundles at once, separate the plants and either pack in boxes or baskets with damp moss, chaff or sawdust, separating the roots or else "heel-in" outdoors.

"Heeling-in" in briefest terms is temporary planting. Dig a trench just deep enough to admit the roots; lay the plants in side by side and cover the roots with earth leaving the crowns exposed.

Trimming: For convenience in planting the roots may be trimmed. In case of heavy root growth the roots may be shortened to four inches in length. Close trimming, to two inches or less, is to be avoided as these short roots will not reach moist soil. Remove all leaves but one or two before planting.

Strawberry plants may be set as close as eighteen inches in the row and the rows four feet apart, but for most varieties twenty-four inches in the row is better. At two by four feet 5,445 plants are required for an acre.

Plants are usually set by the spade method, two persons working in company.

The plant setting machine commonly used for setting tobacco and cabbage plants is also successfully employed in setting strawberry plants on a large scale.

One thing is highly important, viz., the proper depth of setting. If the plants are set too deep the "crown" or growing point is covered; if set too high the roots are exposed. In either case the plant may fail to grow. With a little practice the right way may be found.

Cultivation: Keep the soil loose, mellow and free from weeds throughout the season by frequent cultivation. An adjustable fine-tooth cultivator is a good tool to use. Run close to the plants at first and as the runners stretch out into the 
space between the rows, close up the cultivator allowing the plants to set thickly in matted rows two feet wide, thus leaving a two-foot path between the rows. In case of too vigorous growth attach a rolling coulter to the cultivator to remove the surplus runners. Care should be taken to keep the rows full of plants by training runners so as to fill vacant places.

This is what is known as the "matted row" system, the most practical plan for the average grower. Where there is a demand for very large berries, uniform in size, the single or double "hedge row" or hill system may be adopted.

If the ground is rich and the season favorable too many plants may set. In this case as the season advances remove the surplus until the plants in the row stand about four inches apart.

Remove all blossoms the first season as soon as they appear. All of the energies of the parent plants must be directed to plant making the first season and not wasted in the production of flowers and fruit.

Considerable hoeing and weeding will be needed the first season for the beds must be kept clean. Grass and weeds rob the strawberry plants of food and moisture. We should endeavor to secure a good stand of strong, vigorous, deeply rooted plants the first season; lacking this we cannot expect a profitable crop of fruit next year.

Perfect and Imperfect Flowers: Some varieties of strawberries produce only imperfect flowers. These flowers have no stamens and are therefore incapable of self-pollination. It is important to keep this fact in mind when selecting varieties, for if only imperfect-flowered varieties are selected no fruit will be borne. A part of the plantation at least must be of kinds bearing perfect flowers. Nurserymen indicate in their catalogues the imperfect varieties by the abbreviation "Imp."

Varieties to Plant: The amateur as well as the professional soon learns that in the selection of varieties he must be largely guided by local conditions of soil, climate, etc., and that no list can be given that will be satisfactory over the whole state. However, two varieties, Warfield and Dunlap, seem to give satisfaction over a wider range of soils and climate in Wisconsin than any other standard varieties. Some growers advocate planting only Dunlap. 


\section{Fall Bearing or So-called Everbearing Strawberries}

Within a few years a new group of strawberries has appeared, the so-called "everbearers." These kinds do not, as the name indicates, bear throughout the whole season but produce a crop at the same season as the standard varieties and, after a short rest period, a second and often a third and even a fourth crop, frequently fruiting from June to November.

Enough berries, a straggling few, are borne between crops to partly justify the name "everbearing."

These kinds are most excellent for the home garden but the beginner who is growing for market should not plant heavily of the everbearers but stick to the standard sorts. The experienced grower, especially if he has an irrigation plant, can usually grow them profitably. The most popular kinds are Americus; Progressive and Superb. Progressive seem to be the most prolific; Superb large fruit, and Americus more nearly an all season or everbearer.

Mr. M. S. Kellogg of Janesville, who has grown the "everbearers" since the first commercial varieties appeared, sixteen years ago, has this to say of them:

"This class of fruit has passed the experimental stage and has become a necessity for the home garden and for the commercial grower when conditions of soil and market are favorable. In growing the Everbearers the following is the most approved method of culture. Plant as early in spring as the conditions of soil and weather will permit, keep all bloom removed from the plants until about one month before you wish the fruit to begin to ripen. Allow the plants to produce from four to eight runners and when these are rooted remove all other runners as soon as they appear. You will then have a hedge row or half matted row system and with clean culture and good fertile soil you will get lots of berries. If you want fruit do not let them make too many plants. A bed of Everbearers after having fruited the year of planting should be well covered and can be carried over to fruit the following June if desired or the fruit stem can be kept off the second season until July 15th and they will bear again in the fall. Right varieties, rich soil and good culture will win but the greatest of these is GOOD culture." 
Winter Protection: Strawberry plants must be given winter protection, a iight covering, not so much to prevent freezing as to prevent alternate freezing and thawing. Marsh hay is the ideal material for this purpose. Clean straw is also used but as it usually contains weed seeds hay is preferable. About two tons of hay will be required for an acre which is equivalent to a heavy crop of growing hay.

This covering should be left on until growth starts in the spring when about two-thirds of it should be raked into the spaces between the rows where it will serve to keep down weeds, retain moisture, keep the fruit clean and furnish a "carpet" for the pickers.

The balance of the mulching should be left on the plant row and the plants allowed to push through it. The more mulching left on the row the better so long as the plants are able to work through it as it serves the double purpose of keeping down weeds and retaining moisture.

It is not well to remove any part of the mulch too early in the spring as it serves to retard the growth of the plants and thus furnish security against late frosts. In fact care should be taken to leave the mulch on until the new leaves under the cover show white.

\section{After the First Year}

It is the practice of many growers to harvest but one crop of berries and at the end of the picking season plow under the plants and use the land for a crop of rutabaga, turnip or buckwheat. In favorable seasons late cabbages or the early ma. turing varieties of sweet corn may be planted.

If it is desired to carry the field over another year, after picking cut the plants close to the ground with a mower and after they have dried burn them.

In order to avoid injury to the roots by fire the mowed plants and mulching should be thoroughly dried so as to burn quickly.

No cultivation is given the second season but any strong growing weeds which appear such as dock, thistle, etc., may be readily cut out by the use of a broad chisel attached to a fork handle. The plants are mulched in the fall the same as for the first year.

Strawberries when grown as here advised, by the matted row system, cannot be profitably cropped more than two years. 



\section{TREE FRUITS}

\section{Planning and Planting the Orchard}

Soil and Site: Fruit trees require well drained soil. The character of the soil is of less importance than drainage. Much has been written about the right kind of soil for apples, cherries and plums, great stress being laid on the character of soil necessary to produce paying crops. Some of it is true but a little observation will show many very fine orchards in Wisconsin on wide ranges of soil. The very thin soils of Door county produce wonderful orchards, so also do the deep loamy soils of Crawford county while the very oldest apple trees in the state are growing in the black loams of Jefferson and Rock counties. Don't worry too much about the right kind of soil.

As a commercial proposition it is well to take account of the fact that trees on deep clay loam soil will require longer to come into profitable bearing than those on light, sandy or gravely soils,-and live longer.

For the home orchard of a dozen trees plant near the house regardless of the nature of the soil,-if it is well drained. Many people believe that an orchard should always be planted on sloping ground. This idea probably arises from the fact that our forefathers in Massachusetts and Virginia planted apples on hill sides but this was because it was found that trees would grow there, thus reserving the level land for corn or other crops which required cultivation. Level well drained land is preferable on account of ease of cultivation. If only sloping land is available choose a north slope rather than a south slope.

Air Drainage: This is also important. A free circulation of air through the tree tops hinders the development of disease and insects. If trees are planted in a low spot where cold air settles the fruit buds may suffer from frost.

Causes of Failure: Many thousands of trees are set out every year in this state; some live, many die. 
In some cases the nurseryman is at fault. More often the planter is at fault. The trees may arrive in good condition but in the rush of spring work the bundle is laid aside until a convenient time arrives to plant, or the trees may be improperly planted.

Trees and plants in small lots are packed in bundles at the nursery. If the work is well done the roots are packed in damp moss or excelsior and this covered with burlap. The tops should also be completely covered either with rye straw or burlap. This packing is usually sufficient to protect the plants from drying until they have arrived at their destination, but is not intended to preserve them longer.

Never under any circumstances leave the trees in the shipping package, even over night. If possible plant at once, otherwise open the bundle and "heel-in" the trees or plants.

"Heeling-in" is temporary planting. To do this dig a trench wide and deep enough to accommodate the roots and with one side sloping.

Open the bundle, lay the trees separately in the trench with tops resting on sloping bank. Cover the roots with moist earth sifting it well among the roots, tramping firmly. In addition a mulch of straw or manure will help to preserve moisture. Treated in this manner trees may remain in the trench for several days if it is absolutely necessary to leave them there. If trees are shrivelled when received bend down the tops after heeling-in and cover them with moist earth. Often in two or three days they will be found to be plump and fresh.

Planting: The ground should be deeply plowed and well cultivated before planting. Do not set fruit trees in sod. The grass roots will reach out and rob the trees of food and water. If you cannot devote a piece of land to trees alone and keep it in cultivation, do not attempt fruit growing as the resuits will be disappointing.

Dig holes large enough to accommodate the roots after these have been cut back to sound wood. Trim broken and crushed roots back to sound wood, do not cut off more. Don't worry about the fine, fibrous roots about which so much has been written,- - these are dead anyway if the tree has been out of the ground more than a few hours,-take care of the larger roots for it is from these that growth starts. 
The hole should be deep enough to admit setting the tree about two inches deeper than it stood in the nursery. Spread out the roots, sift fine earth about them and pack firmly with the feet. If the earth is moist and mellow it cannot be tramped too firmly. It must be in close contact with the roots in order to enable them to take up the water it contains.

Pruning: The tree is now safely anchored in the ground but the work is not finished. At this point arises the most common cause of failure: some of the branches must be removed or the tree is apt to perish.

Before removal from the nursery the tree had sufficient roots to supply all of its buds with water. In digging, most of the roots have been (necessarily) removed, but the buds are left. When growth begins every healthy bud will push out and call on the roots for water to feed its newborn leaves. The very limited supply that the reduced root system can pump up will be distributed equally and as a result none may have enough to develop its leaves and without leaves the tree must perish. We must, therefore, reduce the number of these water pumps by removing one-half to three-fourths of the buds.

The drier the ground and weather the more we should cut off. The manner in which the cutting is done will depend to a great extent upon the kind of tree. In apples, plums, etc., we need to bear in mind the ultimate shape of the tree. The frame-work upon which the branch system is built is determined largely at this time. Remove crowding, crossing, and interfering branches. Aim to leave the main branches spirally about the stem rather than opposite. The lower opposite branches in fruit trees form bad forks that may split down later. Don't be afraid to cut; failure will result unless much cutting is done.

Distance to Plant: Apple and crab trees should be planted $24 \times 24$ feet which will require seventy-five trees to the acre.

Piums and cherries may be planted as close as $16 \times 20$ feet but $20 \times 20$ feet is better. At $20 \times 20$ feet 108 trees are required for an acre.

Cultivation and Cropping: The orchard must be cultivated for several years after planting if profitable returns are expected. Weeds and grass must be kept down and the soil stirred to encourage growth. There is no need, however, of 
devoting all of the space between the rows to the trees the first four or five years, hence intercropping is suggested.

Beans, garden peas, potatoes or other hoed crops may be grown without serious detriment to the trees, but corn, except possibly sweet corn, ought not to be planted in the young orchard as it takes too much from the soil and shades the young trees. Cultivation should cease soon after July 1st in order to permit ripening of the wood growth.

Protectors: To prevent damage by mice and rabbits during winter the trunks of the trees should be covered with wire screen or tarred paper. If the paper is used it should be removed in the spring.

Buying Trees: Buy only two year old trees of apple. One year cherry trees if well grown in the nursery are often as good if not better than two year old. Two year old plum trees are usually sent out by nurseries. Buy of Wisconsin nurserymen. We have many reliable nursery firms in our own state who can furnish any of these varieties. Why buy elsewhere?

Place your order in fall or winter for early spring delivery. Do not plant fruit trees in the fall.

\section{Varieties}

Apples: The varieties named below are all standard, reliable and hardy and have been thoroughly tested in Wisconsin for fifty years or more.

For the home orchard of a dozen apple trees the following selection will give satisfaction: 3 Duchess (early), 5 Wealthy (mid-season), 4 Northwestern Greening (winter). If a greater variety is desired add McIntosh (mid-season), Tolman Sweet (winter), and Windsor (winter). For north-central and northern Wisconsin substitute Patten Greening for Northwestern and omit McIntosh.

Do not plant Transcendent crab anywhere in Wisconsin on account of its tendency to blight, plant Martha or Hyslop instead. The commercial grower will want to add to the above. A full list of tested varieties will be found in the Annual Report of this Society. (Sent free to members).

Plums: Surprise, DeSoto, Hawkeye, all natives, all reliably hardy anywhere in Wisconsin and all sure croppers. 
None of the European or Japanese plums are long-lived in Wisconsin but trees of certain varieties often live to bear several crops.

Try: Green Gage, Lombard and Moore's Arctic for European and Burbank for Japanese.

Cherries: Where cherries thrive plant Early Richmond and Montmorency.

Pruning: Prune tops severely as soon as planted, removing 50 to 75 per cent of branches.

Care: Cultivate often enough until midsummer to keep down weeds and grass and to keep soil mellow. 



\section{LIBRARY OF CONGRESS}

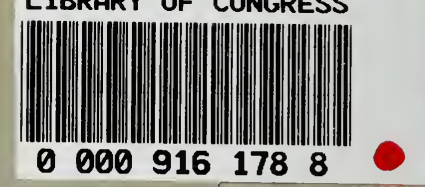

